\title{
Intraoral slow-releasing polymeric patches containing sodium fluoride and chlorhexidine: Development and evaluation
}

\author{
Yarmunja Mahabala Karuna ${ }^{1}$, Swati Pralhad ${ }^{2 *}$, Srinivas Mutalik², Anupama P. Nayak ${ }^{1}$, Bharath Singh Padya ${ }^{3}$ \\ ${ }^{1}$ Department of Paedodontics and Preventive Dentistry, Manipal College of Dental Sciences, Mangalore, Manipal Academy of Higher Education, \\ Light House Hill Road, Mangalore 575001, Karnataka State, India. \\ 2Department of Periodontology, Manipal College of Dental Sciences, Mangalore, Manipal Academy of Higher Education, Light House Hill Road, \\ Mangalore 575001, Karnataka State, India. \\ ${ }^{3}$ Manipal College of Pharmaceutical Sciences, Manipal Academy of Higher Education, Manipal 576104, Karnataka State, India.
}

\begin{tabular}{|c|c|}
\hline ARTICLE INFO & ABSTRACT \\
\hline $\begin{array}{l}\text { Received on: } 06 / 12 / 2019 \\
\text { Accepted on: } 13 / 08 / 2020 \\
\text { Available online: } 05 / 10 / 2020\end{array}$ & $\begin{array}{l}\text { Early childhood caries (ECC) has been considered to be at epidemic proportions in developing countries. There is a } \\
\text { scientific consensus regarding the benefit of a constant supply of low levels of fluoride, especially at the biofilm/saliva/ } \\
\text { tooth interface in preventing dental caries. The use of controlled and sustained delivery systems containing fluoride } \\
\text { can be considered as an effective means of eradicating ECC in high-risk individuals. The use of chlorhexidine as an }\end{array}$ \\
\hline $\begin{array}{l}\text { Key words: } \\
\text { Early childhood caries, } \\
\text { chlorhexidine, sodium } \\
\text { fluoride, slow release of drug, } \\
\text { primary teeth. }\end{array}$ & $\begin{array}{l}\text { antimicrobial agent in combination with fluoride is beneficial (Naidu et al., 2016). Slow-releasing devices containing } \\
\text { both fluoride and chlorhexidine do not exist as of now. Hence, the aim of the present study was to design a slow-release } \\
\text { polymeric intraoral patch containing fluoride and chlorhexidine, and to evaluate the amount of medicament released } \\
\text { over } 20 \text { days. Three slow-releasing patches were fabricated with different concentrations of gelatin to determine } \\
\text { the maximum release of medicaments. Using in-vitro drug release studies it was observed that, out of three patches } \\
\text { prepared with equal concentrations of chlorhexidine }(80 \mathrm{mg}) \text { and sodium fluoride }(288 \mathrm{mg}) \text {, a patch I containing } 1,000 \\
\text { mg of gelatin was found to be beneficial for a sustained release of both medicaments. }\end{array}$ \\
\hline
\end{tabular}

\section{INTRODUCTION}

Dental caries in preschool children remains to be a serious public health problem with biological, social, and behavioral determinants in both developed and developing countries (Colak et al., 2013; Twetman, 2008). Early childhood caries (ECC) has been considered to be at epidemic proportions in developing countries (Weinstein et al., 1994). The consequences of untreated ECC can affect both the immediate and long-term quality of life of the child (Inglehart et al., 2002). This chronic infectious disease of childhood is caused by the interaction of bacteria, mainly Streptococcus mutans, and sugary foods on tooth enamel (Colak et al., 2013). The effective use of fluoride and antimicrobial agents, such as chlorhexidine, may be beneficial

\section{*Corresponding Author}

Swati Pralhad, Department of Periodontology, Manipal College of Dental Sciences, Mangalore, Manipal Academy of Higher Education, Light House Hill Road, Mangalore 575001, Karnataka State, India. E-mail: swati.pralhad@manipal.edu for strengthening the tooth enamel and suppressing the bacterial population, thereby reducing caries risk (Tang et al., 2016).

There is a scientific consensus regarding the benefit of a constant supply of low levels of fluoride, especially at the biofilm/ saliva/tooth interface in preventing dental caries (Featherstone, 1999). It is justified in foreseeing a reduced caries incidence following a treatment independent of patient compliance, which can increase the fluoride concentrations steadily. Shields et al. (1987) demonstrated that irrespective of water fluoridation status, caries-free children had $0.04 \mathrm{ppm}$ or more salivary fluoride levels, whereas those with carious dentitions had only $0.02 \mathrm{ppm}$ or less. Considering that intraoral levels of medicament play a key role in the dynamics of dental caries, it has been suggested that the use of controlled and sustained delivery systems can be considered as effective means of eradicating ECC in high-risk individuals (Pessan et al., 2008).

Chlorhexidine is known to be the gold standard among the antimicrobial agents in use. It is said to be bacteriostatic at low concentrations and bactericidal at high concentration. Delivery methods available for chlorhexidine as of date include mouth rinses, aerosols, gels, dissolvable chips, chewing gum, 
dentifrices, and varnishes (Tang et al., 2016). On the other hand, few slow-releasing intraoral devices have been successfully tried and documented in the literature, but their retention was not satisfactory (Pessan et al., 2008). Also, none of these devices is available readily in the Indian market.

Keeping in mind improved retention, acquiring the added benefit of combining fluoride and chlorhexidine, and to make them available in the Indian market, we designed a slow-releasing intraoral polymeric patch. The present study was conducted to evaluate the release of fluoride and chlorhexidine from the same.

\section{MATERIALS AND METHODS}

The study was initiated after obtaining approval from the Institutional Ethics Committee. It was conducted in two phases. Phase 1 involved the preparation of the slow-releasing intraoral patches. In phase 2, the content of active agents in the patches was determined and the patches were assessed for drug release studies over a period of 20 days.

In this study, we selected different inactive ingredients, viz., gelatin (matrix/patch-forming agent), sodium alginate (gelling agent and provides slow release of drug), glycerin (prevents drying out of the patch by acting as a humectant as well as a platicizer), poly ethylene glycol (provides optimum drug release by acting as pore-forming or wicking agent), methyl paraben (preservative), and propyl paraben (preservative), along with two active ingredients, (sodium fluoride which prevents caries in teeth) and chlorhexidine digluconate (anti-microbial), based on previous literature (Hossain et al., 2014; Li et al., 2016; Pal et al., 2006). We arrived at the optimized formulations (as shown in Table 1) after taking different batches of the patch formulation by varying the composition and concentrations of the inactive ingredients.

\section{Phase 1: preparation of intraoral polymeric patches}

Chlorhexidine digluconate (20\%) was purchased from Unilab Pharmaceuticals, Mumbai, India. Gelatin (from bovine skin), sodium alginate (from brown algae), polyethylene glycol (PEG-4000), glycerol, methyl paraben, propyl paraben, and sodium fluoride $(>99 \%)$ were purchased from Sigma-Aldrich (Saint Louis, MO). All the chemicals used were of analytical/ reagent grade.

The polymeric patches were made using different concentrations of gelatin, which is a medicament release retardant. The gelatin alters the drug release rate. Hence, different concentrations of the same were checked for sufficient release

Table 1. Composition of intraoral dental patches.

\begin{tabular}{lccc}
\hline \multirow{2}{*}{ Ingredients } & \multicolumn{3}{c}{ Quantity of the ingredients (mg) } \\
\cline { 2 - 4 } & Patch 1 & Patch 2 & Patch 3 \\
\hline Chlorhexidine bis gluconate & 80 & 80 & 80 \\
Sodium fluoride & 288 & 288 & 288 \\
Gelatin & 1,000 & 800 & 600 \\
Sodium alginate & 60 & 60 & 60 \\
PEG-4000 & 368 & 368 & 368 \\
Glycerin & 150 & 150 & 150 \\
Methyl paraben & 0.172 & 0.172 & 0.172 \\
Propyl paraben & 0.0172 & 0.0172 & 0.0172 \\
\hline
\end{tabular}

of both sodium fluoride and chlorhexidine. The composition of prepared intraoral polymeric patches is given in Table 1 . The weighed quantity of gelatin (biopolymer; film former) was taken in a beaker containing a small amount of water $(3-5 \mathrm{ml})$ to hydrate the gelatin and was kept aside for 30 minutes. The weighed quantity of sodium fluoride (active constituent; prevents caries in teeth) and sodium alginate (slow release polymer; provides sustained release and aids in mucoadhesion) was added to this and mixed on a water bath at $60^{\circ} \mathrm{C}$ until a homogenous viscous solution was formed. A drop of glycerin (humectant; plasticizer) was then added while stirring continuously. To the same, chlorhexidine digluconate (active ingredient; anti-microbial) was added. Then, poly ethylene glycol (PEG; aids in drug release; wicking agent) was added and it was kept on a water bath while continuously stirring (Hossain et al., 2014). Finally, methyl paraben and propyl paraben (preservatives) were added and mixed properly on a water bath at $60^{\circ} \mathrm{C}$ for 5 minutes. This solution was poured into the mold, which was later kept in the fridge for 3 days. The polymeric patch was removed after complete drying and exposed to formaldehyde vapor for 3 days in order to crosslink gelatin. To aid the proper weighing of chlorhexidine digluconate, the $20 \%$ solution of chlorhexidine was lyophilized for 48 hours (Martin Christ Lyophilizer, Germany) to get a powder form. The image of a slow-releasing intraoral polymeric patch and its proposed attachment onto the tooth surface using a resin is shown in Figure 1.

\section{Phase 2: determination of drug content and in-vitro drug release studies}

A piece of a polymeric patch $\left(25 \mathrm{~mm}^{2}\right)$ from each formulation was taken, sliced using a scissor and crushed by using a mortar with pestle. The crushed material was taken in a beaker, to which $3 \mathrm{ml}$ of hot phosphate buffer, $\mathrm{pH}$ 6.8, was added. It was placed in a waterbath sonicator at $60^{\circ} \mathrm{C}$ for 20 minutes. After dissolving the polymeric patch, the solution was centrifuged at 3,000 rpm for 10 minutes. The absorbance of the supernatant solution was recorded at $251 \mathrm{~nm}$ using a UV spectrophotometer to determine the content of chlorhexidine (Abdelrahman et al., 2016; Fini et al., 2011). To estimate the concentration of chlorhexidine, a calibration was constructed at a concentration range of $0-20 \mu \mathrm{g} /$ $\mathrm{ml}$. The calibration was linear with an $R^{2}$ value of 0.9979 and the corresponding equation was $y=0.035 x-0.016$. The same sample was subjected to UV/Visible spectrophotometric analysis at 570 $\mathrm{nm}$ for fluoride estimation by SPADNS (2-parasulfophenylazo1,8-dihydroxy-3,6-naphthalene-disulfonate) method (Barghouthi and Amereih, 2012). For the estimation of fluoride, a calibration

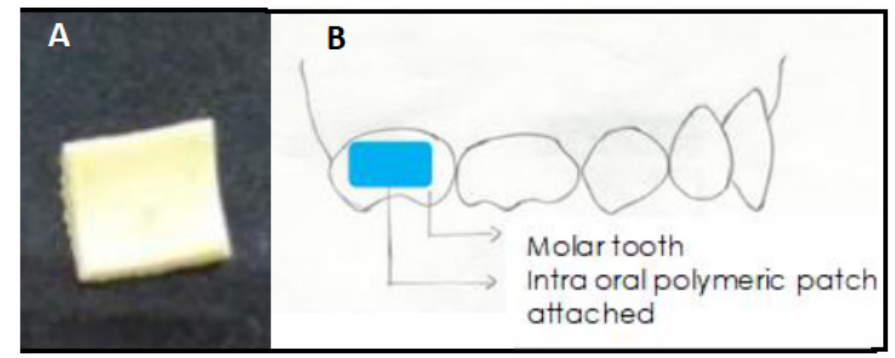

Figure 1. Image of a slow-releasing intraoral polymeric patch (A) and attachment of the slow-releasing intraoral polymeric patch onto the tooth surface (B). 
was constructed using sodium fluoride at a concentration range of 0-30 $\mu \mathrm{g} / \mathrm{ml}$. The calibration curve was linear with an $R^{2}$ value of 0.9605 and the corresponding equation was $y=0.0218 x+0.053$.

The in-vitro release of chlorhexidine from the polymeric patches was carried out by using a vial method at room temperature for 20 days (Amirthalingam et al., 2017; Shen and Burgess, 2012). The polymeric patch (area: $25 \mathrm{~mm}^{2}$ ) from each batch was kept in the glass vials containing $1 \mathrm{ml}$ of phosphate buffer $\mathrm{pH}$ 6.8. The vials were capped with rubber closures. One $\mathrm{mL}$ of the release medium was collected at predetermined time intervals and replaced with $1 \mathrm{ml}$ of fresh buffer. The withdrawn samples were then analyzed for determining the chlorhexidine content using UV spectrophotometer (UV-1700 Pharma Spec, Shimadzu, Japan) at $251 \mathrm{~nm}$. The same sample was subjected to UV/Visible spectrophotometric analysis at $570 \mathrm{~nm}$ for fluoride estimation by SPADNS (2-parasulfophenylazo-1,8-dihydroxy-3,6-naphthalenedisulfonate) method.

\section{RESULTS AND DISCUSSION}

Among the multiple caries preventive strategies available, the use of fluoride has been clinically proven to be the most effective efficient method and the anti-caries effects of fluoride have been unequivocally accepted. The most prescribed fluoride regimens include the form of rinses, gels, varnishes, and dentifrices (Marinho et al., 2016). However, even with easily available cost-effective fluoride regimens and widespread advice from the dentists on the use of fluoride, the status of the caries-free population still remains questionable (Seppä, 2001). The reason for the same is the lack of patient compliance, especially in the high caries risk category. Thus, the current consensus is on the slow and prolonged delivery of fluoride, which is independent of patient compliance (Pessan et al., 2008), thereby leading to the evolution of slow-releasing fluoride devices (Chong et al., 2018; Pessan et al., 2008). The co-polymer membrane (Cowsar et al., 1976) and slow-dissolving fluoride glass beads (Toumba and Curzon, 1993) are the two main types among the popular ones. Inspired by the same we prepared slow-releasing intraoral polymeric patches containing fluoride and chlorhexidine using different combinations of polymers along with evaluating the medicament release by them in vitro.

Chlorhexidine is a wonder antimicrobial agent with both bacteriostatic and bactericidal properties against the bacteria responsible for caries initiation, S. mutans (Haghgoo et al., 2017). This cationic chemoprophylactic agent has shown a cariespreventing ability through multiple studies (Dong et al., 2012; Fennis-le et al., 1998; García-Caballerol et al., 2009; Georgios et al., 2015; Tomás et al., 2010). Also, the benefits of chlorhexidine in the maintenance of healthy periodontium are universally accepted (Pietruska et al., 2006). Chlorhexidine has been incorporated in dentifrices, mouthwashes alike, and in varnishes and gels for its slow release (Fiorillo, 2019; Fini et al., 2011). A combination of chlorhexidine and fluoride has been shown to be beneficial for the reduction of caries. Thus, chlorhexidine was added as one of the medicament to be included while preparing the polymeric patch.

The physical characterization of the patches was performed by visual observation, physical touch, and also by folding the patch in different directions. It was found to be sufficiently hard yet flexible and pale yellow in color. The patches were found to be smooth and were devoid of any imperfections. The thickness of the prepared patches, as measured by digital vernier calipers (Mitutoyo, Japan), was found to be between 1.2 and $1.6 \mathrm{~mm}$. The patches were cut into small pieces of $25-\mathrm{mm}$ square area. The polymeric intraoral patches were prepared using different concentrations of gelatin, which is a medicament release retardant. The use of gelatin alters the drug release rate; hence, different concentrations of the same were checked for sufficient release of both sodium fluoride and chlorhexidine. The percentage of chlorhexidine and sodium fluoride present in all the batches ranged from $95 \%$ to $100 \%$, respectively.

The results of in vitro drug release studies indicated that Patch 1 showed a slow release of $4.3 \mathrm{mg}(90.53 \%)$ of chlorhexidine at the end of 20 days, whereas Patches 2 and 3 did not show prolonged release up to 20 days. They showed a release of chlorhexidine up to $4.85 \mathrm{mg}(100.47 \%)$ and 4.80 $\mathrm{mg}(97.17 \%)$ of chlorhexidine at the end of 17 and 14 days, respectively (Figure 2).

When fluoride release was evaluated, Patch 1 showed $17.15 \mathrm{mg}(99.28 \%)$ of fluoride release at the end of 20 days. Patches 2 and 3 demonstrated a release of $17.07 \mathrm{mg}(99.86 \%)$ and $16.86 \mathrm{mg}$ (98.63\%) of fluoride at the end of 18 and 15 days, respectively. As in the case of chlorhexidine, Patches 2 and 3 with fluoride too did not show prolonged release up to 20 days (Figure 3 ).

Thus, in the present study, Patch 1 polymeric patch showed a sustainable slow release of medicaments, viz., fluoride and chlorhexidine, over a period of 20 days. The only variation observed between the three patches was the difference in the amount of gelatin concentration. Gelatin is a non-toxic and biodegradable soluble protein hydrolyzed from collagen with negligible antigenicity ( $\mathrm{Li}$ et al., 2016). It is a heterogeneous single or multi-stranded polypeptide. Solutions undergo coilhelix transition, which is followed by the aggregation of the helices by the formation of collagen-like, right-handed, triplehelical proline/hydroxyproline-rich junction zones. Gelatin is a well-known biopolymer that acts as a film former, as well as controls the drug release for sustained release. Gelatin acts as a strengthening agent as well since it also gets cross-linked in the presence of formaldehyde vapors which further enables it to hold the medicament more tightly to provide further sustained release of drugs (Pal et al., 2006).

The polymeric patches used in the present study are different from the copolymer membrane developed by Cowsar et al. (1976). The copolymer membrane was a trilaminate device (inorganic fluoride salt core dispersed in the hydrogel of hydroxyethyl methacrylate and methyl methacrylate, which in turn is coated by a semi-permeable, rate-controlling membranes of the hydrated acrylic copolymer) to release fluoride when placed in the oral cavity at constant predetermined linear rates of $0.02-1.0$ $\mathrm{mg} /$ day, while we developed intraoral polymeric patches in which the medicaments were dispersed within polyethene glycol and gelatin matrix. PEG is used for designing numerous biomaterials, including bio-adhesives, mainly because of its biocompatibility and non-immunogenicity. The incorporation of gelatin with the PEG improves its mechanical, adhesive, and bioactive properties (Li et al., 2016).

It is desirable to achieve a minimum of $0.04 \mathrm{ppm}$ of salivary fluoride concentration to achieve a caries-free state 


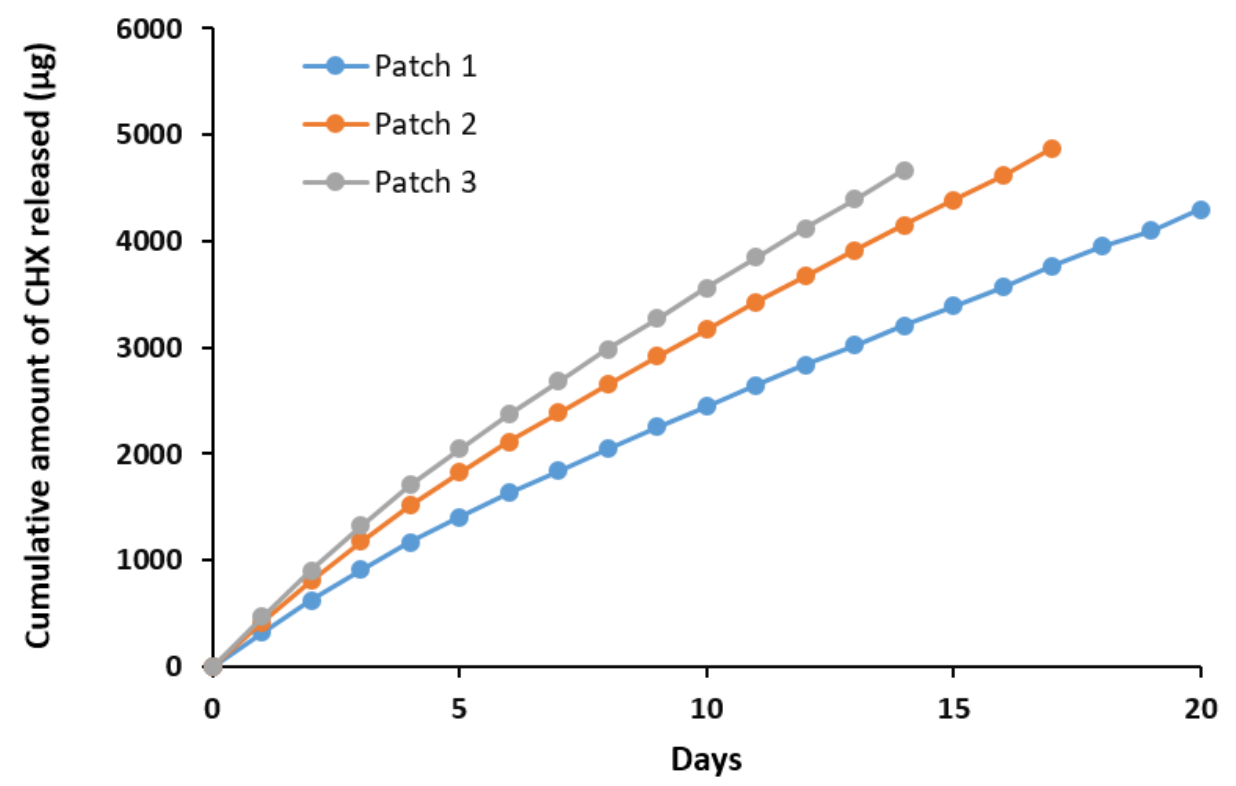

Figure 2. Results of in-vitro chlorhexidine release study of different batches of intraoral patches. In vitro drug (CHX) release profile of chlorhexidine from Patch 1 (1,000 $\mathrm{mg}$ of gelatin), Patch 2 (800 $\mathrm{mg}$ of gelatin), and Patch 3 $(600 \mathrm{mg})$ of gelatin. $\mathrm{CHX}=$ Chlorhexidine .

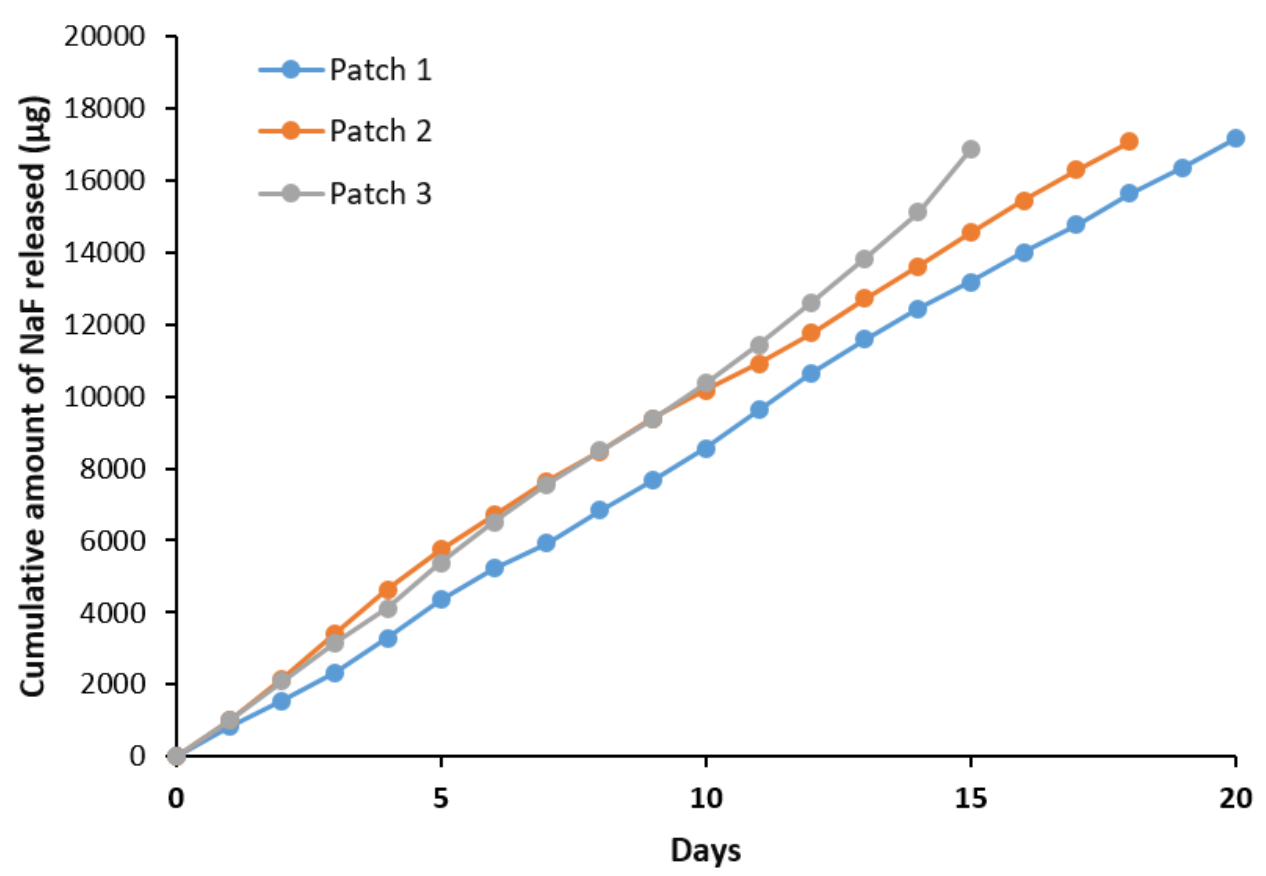

Figure 3. Results of in-vitro sodium fluoride release of different batches of intraoral patches synthesized. In vitro drug $(\mathrm{NaF})$ release profile of sodium fluoride from Patch 1 (1,000 $\mathrm{mg}$ of gelatin), Patch 2 (800 $\mathrm{mg}$ of gelatin), and Patch $3(600 \mathrm{mg})$ of gelatin. $\mathrm{NaF}=$ Sodium fluoride.

(Pessan et al., 2008). On the other hand, minimum, bactericidal, and bacteriostatic concentrations of $0.2 \%$ chlorhexidine are 0.5 and $1 \mathrm{mg} / \mathrm{ml}$, respectively (Haghgoo et al., 2017). Thus, the patch size should be adjusted to each patient accordingly to obtain desirable concentrations of the medicament in the saliva. The cut polymeric patches can be attached onto the buccal/palatal/lingual surfaces of the primary molars with the help of either glass ionomer cement or flowable composite resin (Fig. 1). 
In the present study, we have attempted only to characterize the patch, while studying the in-vitro drug release profile. The polymeric patches used were flexible and thin in contrast to the glass bead type and the copolymer type of slow-releasing fluoride devices (Cowsar et al., 1976) and slowdissolving fluoride glass beads (Toumba and Curzon, 1993). This may have added benefits of more patient comfort (less bulky) and better retention (flexibility allows better attachment to the tooth surface). However, these need to be proven through future studies. Moreover, their clinical efficacy to release fluoride and chlorhexidine, while preventing dental caries and improving the periodontal health, needs to be evaluated in vivo.

\section{CONCLUSION}

The present work explains the successful preparation and in-vitro evaluation of a polymeric patch containing dual drugs, viz., chlorhexidine bis gluconate and sodium fluoride, which can be used in children and adults. A slow-releasing polymeric patch (Patch I) containing fluoride $(288 \mathrm{mg})$ and chlorhexidine (80 $\mathrm{mg}$ ) with gelatin content of $1,000 \mathrm{mg}$ showed to demonstrate the sustained release of the medicaments over a period of 20 days. Detailed antimicrobial studies are further needed to establish the efficacy of the optimized patch. All the ingredients used in the preparation of the patch appear to be safe and nontoxic; however, the developed patches are to be assessed for residual amount of formaldehyde and detailed toxicity and safety studies.

\section{ACKNOWLEDGMENTS}

The authors are thankful to the Manipal College of Pharmaceutical Sciences, Manipal, and Manipal College of Dental Sciences, Mangalore, Manipal Academy of Higher Education, for providing necessary facilities and support. The authors are also thankful to the All India Council for Technical Education (AICTE), Government of India, New Delhi, for the National Doctoral Fellowship to Mr Bharath Singh Padya.

\section{CONFLICT OF INTEREST}

The authors declared that there are no conflicts of interest.

\section{FUNDING}

None.

\section{REFERENCES}

Abdelrahman MM, Naguib IA, Elsayed MA, Zaazaa HA. Spectrophotometric methods for quantitative determination of chlorhexidine gluconate and its major impurity, metabolite and degradation product: parachloro-aniline. Anal Chem Lett, 2016; 6(3):232-48.

Amirthalingam M, Kasinathan N, Amuthan A, Mutalik S, Reddy MS, Udupa N. Bioactive PLGA-curcumin microparticle-embedded chitosan scaffold: in vitro and in vivo evaluation. Artif Cells Nanomed Biotechnol, 2017; 45(2):233-41.

Barghouthi Z, Amereih S. Spectrophotometric determination of fluoride in drinking water using aluminium complexes of triphenylmethane dyes. Water SA, 2012; 38(4):543-8.

Chong LY, Clarkson JE, Dobbyn-Ross L, Bhakta S. Slow-release fluoride devices for the control of dental decay. Cochrane Database Syst Rev, 2018; 3:CD005101.

Colak H, Dülgergil CT, Dalli M, Hamidi MM. Early childhood caries update: a review of causes, diagnoses, and treatments. J Nat Sci Biol Med, 2013; 4:29-38.
Cowsar D, Tarwater O, Tanquary A. Controlled release of fluoride from hydrogels for dental applications. In: Andrade JD (ed.). Hydrogels for medical and related applications. Washington, DC: American Chemical Society, pp 180-97, 1976.

Dong L, Tong Z, Linghu D, Lin Y, Tao R, Liu J, Tian Y, Ni L. Effects of sub-minimum inhibitory concentrations of antimicrobial agents on Streptococcus mutans biofilm formation. Int J Antimicrob Agents, 2012; 39:390-5.

Featherstone JD. Prevention and reversal of dental caries: role of low level fluoride. Community Dent Oral Epidemiol, 1999; 27:31-40.

Fennis-le YL, Verdonschot EH, Burgersdijk RC, König KG, van 't Hof MA. Effect of 6-monthly applications of chlorhexidine varnish on incidence of occlusal caries in permanent molars: a 3-year study. J Dent, $1998 ; 26: 233-8$.

Fini A, Bergamante V, Ceschel GC. Mucoadhesive gels designed for the controlled release of chlorhexidine in the oral cavity. Pharmaceutics, 2011; 3(4):665-79; doi: 10.3390/pharmaceutics3040665

Fiorillo L. Chlorhexidine gel use in the oral district: a systematic review. Gels, 2019; 5(2):31; doi:10.3390/gels5020031

García-Caballero L, Carmona IT, González MC, Posse JL, Taboada JL, Dios PD. Evaluation of the substantivity in saliva of different forms of application of chlorhexidine. Quintessence Int, 2009; 40:141-4.

Georgios A, Vassiliki T, Sotirios K. Acidogenicity and acidurance of dental plaque and saliva sediment from adults in relation to caries activity and chlorhexidine exposure. J Oral Microbiol, 2015; 7:26197.

Haghgoo R, Mehran M, Zadeh HF, Afshari E, Zadeh NF. Comparison between antibacterial effect of chlorhexidine $0.2 \%$ and different concentrations of cyperus rotundus extract: an in vitro study. J Int Soc Prev Community Dent, 2017; 7:242-46.

Hossain SM, Islam S, Saha M, Islam S. Effect of formulation variables on the release of letrozole from natural biodegradable polymeric implants. Br J Pharm Res, 2014; 20:2417-35.

Inglehart MR, Filstrup SL, Wandera A. Oral health and quality of life in children. In: Inglehart M, Bagramian R (ed.). Oral health-related quality of life. Chicago, IL: Quintessence Publishing Co, pp 79-88, 2002.

Li Y, Meng H, Liu Y, Narkar A, Lee BP. Gelatin microgel incorporated poly(ethylene glycol)-based bioadhesive with enhanced adhesive property and bioactivity. ACS Appl Mater Interfaces, 2016; 8:11980-9.

Marinho VC, Chong LY, Worthington HV, Walsh T. Fluoride mouthrinses for preventing dental caries in children and adolescents. Cochrane Database Syst Rev, 2016; 29;7:CD002284.

Naidu S, Tandon S, Nayak R, Ratnanag PV, Prajapati D, Kamath N. Efficacy of concomitant therapy with fluoride and chlorhexidine varnish on remineralization of incipient lesions in young children. Int J Clin Pediatr Dent, 2016; 9(4):296-302; doi:10.5005/jp-journals-10005-1381. Epub 2016 Dec 5. PMID: 28127159; PMCID: PMC5233694.

Pal K, Banthia AK, Majumdar DK. Polyvinyl alcohol--gelatin patches of salicylic acid: preparation, characterization and drug release studies. J Biomater Appl, 2006; 2:75-91.

Pessan JP, Al-Ibrahim NS, Buzalaf MA, Toumba KJ. Slowrelease fluoride devices: a literature review. J Appl Oral Sci, 2008; 16:23846.

Pietruska M, Paniczko A, Waszkiel D, Pietruski J, Bernaczyk A. Efficacy of local treatment with chlorhexidine gluconate drugs on the clinical status of periodontium in chronic periodontitis patients. Adv Med Sci, 2006; 51:162-5.

Seppä L. The future of preventive programs in countries with different systems for dental care. Caries Res, 2001; 35:26-9.

Shen J, Burgess DJ. Accelerated in-vitro release testing methods for extended-release parenteral dosage forms. J Pharm Pharmacol, 2012; 64(7):986-96.

Shields CP, Leverett DH, Adair SM, Featherstone JDB. Salivary fluoride levels in fluoridated and non-fluoridated communities. J Dent Res, 1987; 141:Abst 277. 
Tang X, Sensat ML, Stoltenberg JL. The antimicrobial effect of chlorhexidine varnish on mutans streptococci in patients with fixed orthodontic appliances: a systematic review of clinical efficacy. Int J Dent Hyg, 2016; 14:53-61.

Tomás I, Cousido MC, García-Caballero L, Rubido S, Limeres J, Diz P. Substantivity of a single chlorhexidine mouthwash on salivary flora: influence of intrinsic and extrinsic factors. J Dent, 2010; 38:541-6.

Toumba KJ, Curzon ME. Slow-release fluoride. Caries Res, $1993 ; 27: 43-6$

Twetman S. Prevention of early childhood caries (ECC)--review of literature published 1998-2007. Eur Arch Paediatr Dent, 2008; 9:12-8.

Weinstein P, Domoto P, Koday M, Leroux B. Results of a promising open trial to prevent baby bottle tooth decay: a fluoride varnish study. ASDC J Dent Child, 1994; 61:338-41.
How to cite this article:

Karuna YM, Pralhad S, Mutalik S, Nayak AP, Padya BS. Intraoral slow-releasing polymeric patches containing sodium fluoride and chlorhexidine: Development and evaluation. J Appl Pharm Sci, 2020; 10(10):030-035. 